\title{
Percutaneous Disc Coagulation Therapy (PDCT) comparing with Automated Percutaneous Lumbar Discectomy (APLD) in Patients of Herniated Lumbar Disc Disease: Preliminary Report
}

\author{
Cheon Wook Park, Joo Yong Lee, Woo Jin Choi, Sang Keun Chang \\ Department of Neurosurgery, KonKuk University College of Medicine, Seoul, Korea
}

Objective: Percutaneous techniques are rapidly replacing traditional open surgery. This is a randomized controlled trial study of clinical outcomes of Percutaneous Plasma Disc Coagulation Therapy (PDCT) in patients with HLD(herniated lumbar disc) as a new percutaneous access in comparison with Automated Percutaneous Lumbar Discectomy (APLD) in its clinical application and usefulness as a reliable alternative method.

Methods: The authors analyzed 25 patients who underwent PDCT randomized 1:1 to 25 who underwent APLD between June, 2010 and October, 2011. All patients had herniated lumbar disc diseases. The clinical outcomes were evaluated using Visual Analog Scales (VAS) score and MacNab's criteria.

Results: The age of the patients who underwent PDCT ranged from 29 to 88 years with a mean age of 51.8 years. The age of the APLD undergone patients' population ranged from 30 to 66 with a mean age of 46.0 years. The average preoperative VAS score in PDCT was 7.60 and 1.94 at 7 months post-operatively, and in APLD was 7.32 , and 3.53 at 7 months postoperatively ( $p<0.001)$. In Macnab's criteria, 20 patients $(80 \%)$ had achieved favorable improvement (excellent and good) in PDCT group. In Macnab's criteria, 16 patients (64\%) had achieved favorable improvement in APLD group ( $p<0.001)$.

Conclusion: PDCT can be considered a viable option as a new percutaneous access to herniated lumbar disc. PDCT showed to be more effective than APLD in this study, allowing stable decompression and safe minimally invasive operation to an area desired by the operator in lumbar disc herniation patients, although further long term clinical evaluations are still necessary

Key Words: PDCT - APLD · Herniated lumbar disc

\section{INTRODUCTION}

Disc herniation is one of the most common spinal diseases, and lumbar open discectomy is the most frequently used methods for treating lumbar disc herniation that requires spinal surgery ${ }^{4,16}$. However, this needs an incision dissection of muscles and ligament which may cause undesirable results to lumbar spine post-operatively ${ }^{14,24)}$. Percutaneous techniques are rapidly replacing traditional open surgery in operations requiring discectomy, decompression, and fusion. The percutaneous access to the disc was first used in the 1950s to biopsy the disc with needles. Percutaneous access to the disc using

- Received: April 30, 2012 - Revised: September 8, 2012

- Accepted: September 26, 2012

Corresponding Author: Sang Keun Chang, MD

Department of Neurosurgery, KonKuk University Hospital, 4-12 Hwayang-

dong, Gwangjin-gu, Seoul 143-729, Korea

Tel: +82-2-2030-7355, Fax: +82-2-2030-7359

Email: 19890014@kuh.ac.kr endoscopic techniques was developed in the $1970 \mathrm{~s}^{1,2)}$.

Technical advances in the use of intradiscal therapies led to the development of intradiscal electrothermal annuloplasty (IDET), DISC Nucleoplasty, and DeKompressor, along with laser-assisted, endoscopic, and Nucleotome disc decompressions ${ }^{1,2,7,8,16,21,23)}$.

Onik, a radiologist, recognizing the similarity between vitreous material of the eye and the nucleus of the disc, proposed the use of redesigned ophthalmic equipment for this purpose, now known as Nucleotome $\mathrm{e}^{2021,25)}$.

We compared the effectiveness of PDCT to APLD as a new percutaneous access to herniated disc. Percutaneous Disc Coagulation Therapy (PDCT) was invented to supplement laser treatment. PDCT uses plasma light that the rays generated in the module are concentrated at the end of the fiber and do not travel in a straight line. The concept was considered a suitable and ideal method in disc therapy. PDCT can provide sufficient energy and transfer it to the lesion area without surrounding soft and neural tissues. So far, no randomized trial concerning effectiveness of PDCT versus APLD has been 
performed. We present the design of a randomized controlled trial, studying the effectiveness of PDCT versus APLD in patients with herniated lumbar disc disease.

\section{MATERIALS AND METHODS}

This study was conducted to evaluate efficacy of PDCT and APLT in patients with herniated lumbar disc disease. A twogroup randomized controlled clinical trial was undertaken between June 2010 and October 2011 where 50 patients were enrolled. However, this study was not approved by the institutional review board. 25 patients underwent PDCT, and the other 25 patients underwent APLD. There were 12 men and 13 women with a mean age of 51.8 years (range 29 to 88) in the PDCT group. There were 8 men and 17 women with a mean age of 46.0 years (range 30 to 66 ) in the APLD group. Patients were selected for APLD or PDCT if there were predominant leg symptoms, a radicular pain distribution, restricted straight-leg raise and positive signs of nerve-root tension. We excluded those with symptoms suggestive of facet arthrosis or neurogenic claudication and those whose plain radiographs showed more than $50 \%$ loss of disc height at the relevant level. The inclusion criteria were set as below; (1) Patients with lower extremity radiating pain causing inconvenience in everyday life and having clinical opinions of muscular disorder and positive straight leg raising test inconsistent with MRI findings; (2) Patients who showed no improvement after conservative medical care of more than six weeks; (3) Patients who had no rupture into spinal cavity and/or accessory bone, and/or lumbar calcification known to have no percutaneous operation effect were preferentially selected; (4) Patients who had psychological reasons of compensation resultant from automobile and/or industrial accidents were not operated (Fig. 1). A summary of contraindication criteria are noted in Table 1.

We evaluated clinical outcomes and postoperative complications 1 month and 7 months later after the procedure. Preoperative, 1 month, and 7 months follow-up Visual Analog Scales (VAS) for radiculopathy were measured in this study. The measurement was assessed using a 10-point VAS with endpoint anchors of no pain ( 0 points) and severe pain (10 points).

Results were scored according to Macnab's criteria and cate- gorized as excellent, good, fair, or poor. Patients with an excellent rating showed improvement in at least $80 \%$ of the preoperative symptoms, with not more than $10 \%$ deterioration. Those patients scored as good improved in at least $70 \%$ of the preoperative signs and symptoms and had no more than $15 \%$ deterioration. Patients with a rating of fair improved in at least $50 \%$ of the preoperative signs and symptoms and had no more than $20 \%$ deterioration. Lastly, patients considered as poor, improved in less than $50 \%$ of the preoperative signs and symptoms, or had more than $20 \%$ deterioration.

Pre- and postoperative VAS scores for radiculopathy were compared using two-sample t-tests paired for means. A P value of $<0.05$ was regarded as significant. The chi-square test was used for the calculation of significance in the univariate comparison for the difference of Pre-post VAS.

\section{Equipment of PDCT}

PDCT (Percutaneous Disc Coagulation Therapy) is a type of therapeutic system for disc coagulation, vaporization and decompression with plasma light. It has maximized safety and efficiency compared to normal minimal invasive herniated disc surgery which has been using the conventional lasers or radiofrequency. Since the Plasma D30 system's group pulse mode and stable plasma light which has less than $5 \%$ of straightness, it enables the surgeons to apply thermal damage in selected area only which makes irradiation near nerves safer. At the primary stage, an optimized cavity is formed within the disc. As a result, the internal pressure is decreased, releasing the pressure on the nerve by nucleus pulpous. Simultane-
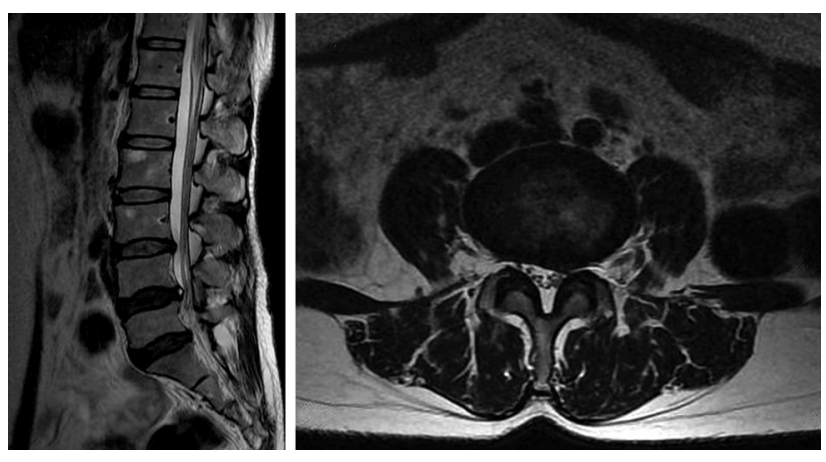

Fig 1. Indication for APLD and PDCT.

Table 1. Contraindication for percutaneous disc decompression

Contraindication for percuataneous disc decompression

- Large, non-contained disc herniation, sequestration or extrusion Exquvocal results of provocative and analgesic discogram infection

- Cauda equina syndrome or newly developed signs of neurological deficit Patients unable to understand informed consent protocol Uncontrolled coagulopathy and bleeding disorders 

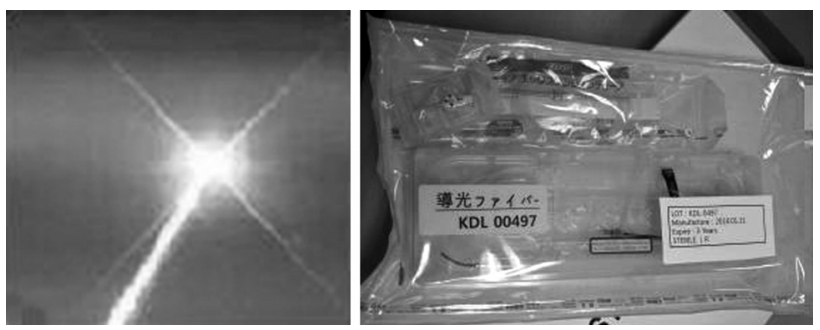

Fig. 2. The image of Plasma light and kit contents.
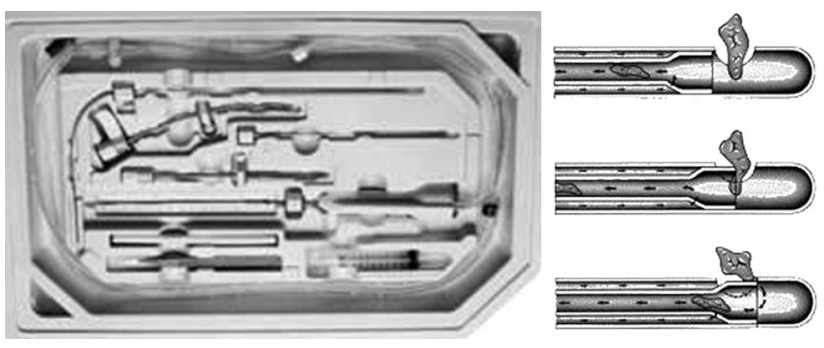

Fig. 3. Image of APLD kit contents.

ously, the protein organization around the released part is fixed solidly, preventing second release. The most advanced theory of PDCT is that PDCT can delivery stable thermal damage to the center of nucleus puplosus and annulus part as well with ball shaped Plasma light (Fig. 2).

\section{APLD (Percutaneous Automated Nucleotome)}

The Nucleotome uses an automated shaver and continuous irrigation to remove disc nucleus. Surgical instruments are available for use through the working cannula giving physicians the capability to reach the desired end point. The Nucleotome has a blunt distal tip and produces no heat, which translates to safety and patient comfort. This technique and equipment permits direct removal of ruptured disc as well (Fig. 3).

\section{Surgical procedure}

\section{1) PCDT}

A patient is basically prepared in a prone position, and under C-arm guide, and a sufficient area is sterilized to be draped with a disposable sterile swab. Entry point is started at 8-10 cm away from lateral in spinous process, and a stabbing position is determined under c-arm guide with local anesthesia. Approach $1.2 \mathrm{~mm}(18 \mathrm{G})$ needle insert on the symptomatic and place the needle at the center of nucleus pulposus (Fig. 4). Attach 3way valve, ex-tube and plasma fiber. Lastly, apply PDCT light 250 Jules at 2 points around center area and with-
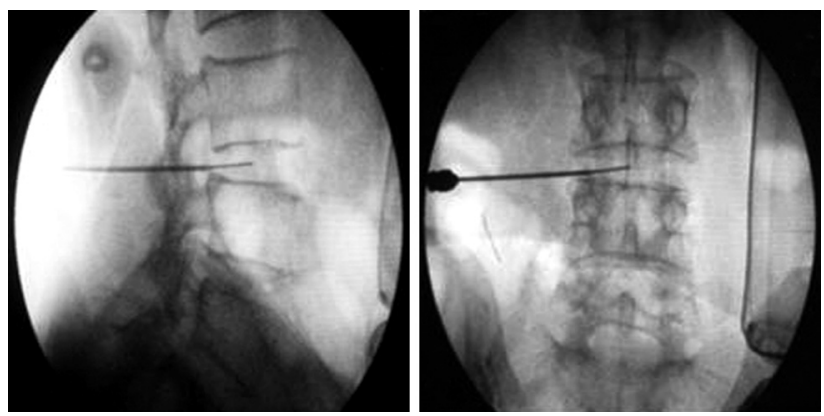

Fig. 4. Plasma fiber working points in disc.

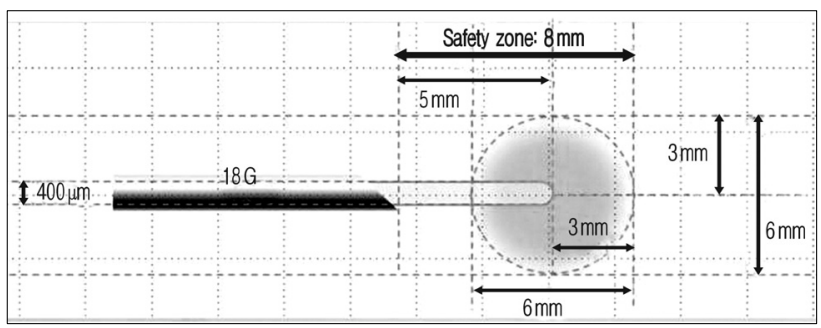

Fig. 5. Drawing of plasma fiber thermal damage area.
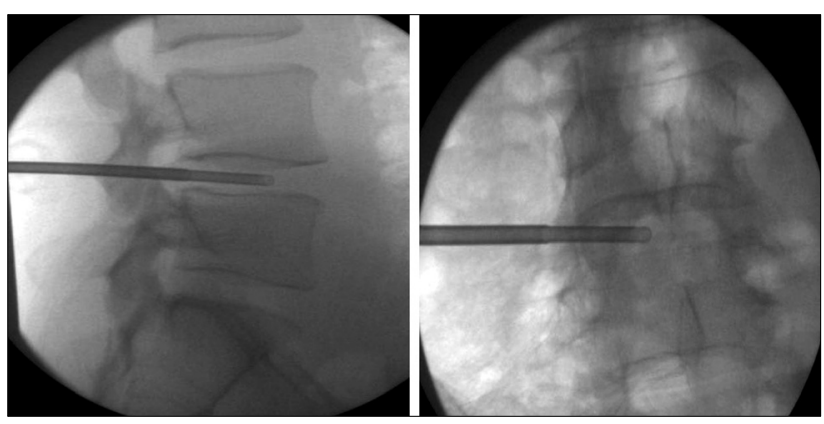

Fig. 6. Image of APLD working cannula at disc.

drawal needle to the annulus area and apply PDCT light 200 Jules-250 Jules to make that area be tighten. Patients discharged from the hospital within one day (Fig. 5.).

\section{2) APLD}

After administering local anesthesia, insert a small guide probe into to disc under the C-arm guidance. Over the probe, a slightly larger tube is inserted down to the annulus and a $1 / 8$ inch opening is made into the disc itself. $2 \mathrm{~mm}$ diameter Nucleotome probe is then inserted through the tube and into the disc (Fig. 6.). We used a standard technique (Maroon et at 1989) with a $2 \mathrm{~mm}$ diameter nucleotome (Surgical Dynamics Inc. Alameda, California). The Nucleotome probe is used to remove small pieces of the nucleus and suction some nucleus out of the disc. The procedure takes about 45 minutes. On 
Table 2. Comparison between PDCT and APLD

\begin{tabular}{lll}
\hline \hline & \multicolumn{1}{c}{ PDCT } & APLD \\
\hline Patients's number & $\begin{array}{c}25 \text { (12 men } \\
\text { and } 13 \text { women) }\end{array}$ & $\begin{array}{r}25 \text { (8 men } \\
\text { and } 17 \text { women) }\end{array}$ \\
$\begin{array}{l}\text { Mean age } \\
\text { 5y } 1.8 \text { years (29 to } 88)\end{array}$ & $\begin{array}{l}46.0 \text { years (30 to 66) } \\
3.5 \text { months }\end{array}$ \\
Symptom duration & 3.3 months & \\
Mean VAS & & 7.32 \\
Pre & 7.60 & 4.29 \\
Post & 2.73 & 2.45 \\
1 month F/U & 2.22 & 3.53 \\
7 month F/U & 1.94 & \\
Macnab's criteria & & 7 \\
Excellent & 14 & 9 \\
Good & 5 & 7 \\
Fair & 5 & 2 \\
Poor & 1 & \\
\hline
\end{tabular}

each occasion the amount of disc material aspirated was recorded. Patients were discharged from hospital within one day.

\section{RESULTS}

50 patients were included in this study. 25 patients $(12$ men and 13 women) whose mean age was 51.8 years were included in PDCT group. 25 patients whose mean age was 46.0 years were included in APLD group. Mean symptom duration were 3.3 months and 3.5 months respectively. Reassessment of the patient's VAS score and Macnab's criteria were accompanied with clinical examination at 1 month after the procedure. There were no complications related to the procedure during the followed period. The mean pre-PDCT VAS score was 7.60 (range 5 to 10). VAS score was decreased down to 2.73 immediately after the procedure and well maintained during the follow-up period. VAS score was decreased to 1.94 after 7 months. This represents a mean reduction of the VAS score which was statistically significant $(\mathrm{p}<0.001)$ by paired T-test (Table 2). The mean pre-APLD VAS score was 7.32 (range 5 to 10 ). VAS score was decreased down to 4.29 immediately after the procedure and 1 month follow up VAS was 2.45 . However, 7 months follow-up VAS score was slightly increased up to 3.53. This represents a mean reduction of the VAS score which was statistically significant $(\mathrm{p}<0.001)$ by paired T-test (Fig. 7).

Macnab results were excellent in 14 patients, good in 6 patients, fair in 4 patient and poor in 1 patient in the PDCT group. 20 patients (80\%) showed excellent and good clinical result in Macnab's criteria right after the procedure. The four patients with fair outcome had 50\% reduction of radiculopathy after the procedure and had been taking mediations as conservative treatment. Macnab results were excellent in 7

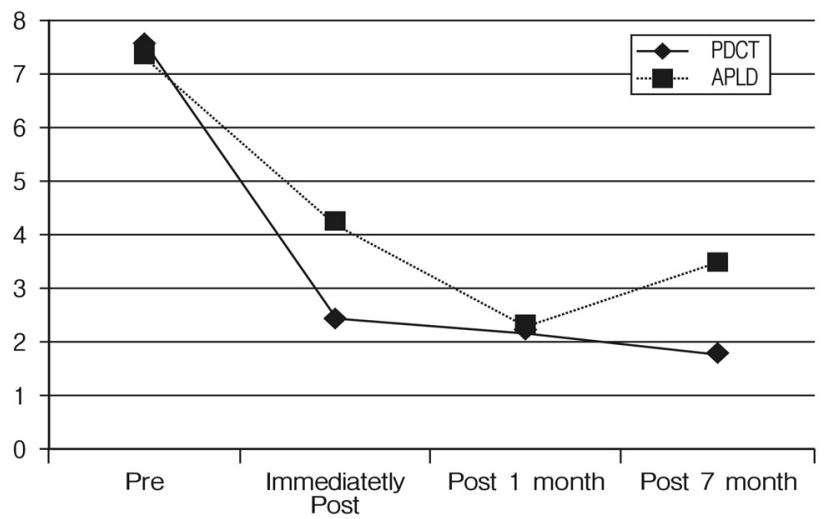

Fig 7. Mean VAS score improved from 7.55 to 1.8 until final follow up in PDCT group and VAS score improved from 7.36 to 3.5 until final follow up in APLD.

patients, good in 9 patients, fair in 7 patient and poor in 2 patients in the APLD group. 16 patients (64\%) showed excellent and good clinical result in Macnab's criteria right after the procedure. Seven patients with fair outcome had 50\% reduction of radiculopathy after the procedure and had been taking pain medications. The two patients with poor outcome showed no improvement after the procedure and needed conversion to open discectomy.

\section{DISCUSSION}

Traditionally, decompression procedures, whether open or percutaneous, have been used to remove a herniated disc compressing neural structures and causing radicular pain and radiculopathy. Herniated discs, however, also include small 2 to $4 \mathrm{~mm}$ disc protrusions, and many interventionalists and surgeons even consider discogram-identified annular tears without a significant protrusion as a type of subligamentous protrusion. Patients with small discal protrusion or annular tears with more back pain than extremity pain are debated whether or not to include them as candidates for percutaneous decompression. Both surgical endoscopy and percutaneous nucleotomy procedures are commonly used to treat this structural pathology. Smaller protrusions are postulated to cause referred extremity pain due to neural inflammation and axial pain due to a combination of a sensitized outer annulus and increased outer annular tension ${ }^{3,6,15,22,23)}$. During surgical endoscopy, the most common finding is an inflamed outer annulus adjacent to the disc protrusion. Directly removing the herniated disc within the protrusion is the most logical goal for decreasing outer annular inflammation and pressure. The medium and smaller diameter techniques, however, were not designed to remove nucleus directly behind the protrusion and, unless the 
protrusion lies in the path of the posterolateral approach, directly removing the source of inflammation is not achieved. Several studies have, however, reported reduction in inflammatory cytokines in rabbits and in Petri dishes following nuclear laser heat vaporization and bipolar radiofrequency heat ablation $^{11,19)}$. The most often stated goal of central nuclear decompression is to lower the pressure in the nucleus and to allow room for the herniated fragment to implode inward. The theory postulates that intact outer annular fibers will be able to contract enough to reduce the tension on both the nerve root and annulus. While sounding logical, there is little proof this actually occurs. In fact, Delamarter et al. ${ }^{9)}$ reviewed the MRI scans of 33 patients with radicular pain due to a disc herniation before and after APLD decompression and saw no measurable changes in six weeks.

The goal of lowering the pressure in the nucleus has been documented in cadaver and animal studies. Using 350 joules of laser energy delivered by a Nd:YAG laser, Yonezawa et $\mathrm{al}^{26)}$ vaporized central nuclear tissue in rabbit discs, creating a hole in the nucleus that, over an eight week period, gradually filled with fibrous tissue. The immediate effect was to lower the vertically measured intra-discal pressure by about $50 \%$. Similarly, Choy and Altman ${ }^{6}$ used 1,000 J from a Nd:YAG, 1.32 micron laser delivered through a quartz fiber to lower the mean intradiscal pressure in cadaver discs by about $43 \%$. Using nuclear coblation, Chen et al. ${ }^{5)}$ showed a 100\% drop in pressure in normal discs in young cadavers, but a negligible drop in pressure in degenerated discs after making six channels within each disc by advancing the Spine Wand(ablation) and retracting it (coagulation) with coblation energy. Although nuclear pressure can be lowered by ablating central nuclear tissue, no one has actually measured the tensional forces in the outer annulus following nuclear ablation. Increasing nuclear pressure by injecting the disc with fluid will be reflected as a proportional increase in outer annular pressure when a radial annular tear extends to the outer annulus ${ }^{6,20,21)}$. This increased pressure is probably analogous to compressing a wellhydrated nucleus and transmitting horizontal forces through the herniated nuclear Masingh and Derby. Regardless of how much nucleus is removed, it is prudent to remove the herniated nucleus within the protrusion and as close to the outer annulus as possible. By using a more lateral approach, one can place the introducer needles or cannulae in a more posterior position. Also, if one is careful not to damage the healthy annulus by not straying into the epidural space, one should be able to safely perform a more localized decompression. In this respect, herniations with a broad base should be easier and perhaps safer to decompress than narrow-necked herniations. Ohnmeiss et al. ${ }^{18)}$ reported a $70.7 \%$ success rate when
APLD decompression was based on the results of a positive discogram and only a $44 \%$ success rate in cases where a discogram was not performed. Similarly, Botsford ${ }^{2)}$ found an overall success rate of $73 \%$ following posterior lumbar laser decompression.

PDCT is invented to correct and improve this directional property of conventional lasers in 2006. PDCT uses plasma laser. The major difference of the plasma light from conventional laser is that the rays generated in the module are concentrated at the end of the fiber and do not travel linearly. The plasma light without directionality creates fireball and provides sufficient effect with the least output power because all the energy is concentrated at the tip of the fiber. Even though energy output is excessive, the surrounding tissues including nerves are safe. Three lesions which are made by fireball are communicated each other and the sufficient decompression of intradiscal volume can be achieved. In view of our clinical experience, PDCT was more effective when performed under following circumstances.

To have a higher success rate both of APLD and PDCT must follow below factors.

1) Relatively young ages.

2) Cases of relatively late occurrence of diseases.

3) MRI findings consistent with disc herniation.

4) Lesser degenerative changes

5) Check the height of disc in case of APLD, low success rate is expected in low disc height.

Complications of percutaneous disc decompression procedure include catheter breakage, nerve root injuries, post-operative disc herniation, cauda equina syndrome, infection, epidural abscess, spinal cord damage, and osteonecrosis , $^{8,10,12-14,17,22,25)}$. In this study, there was no surrounding tissue damages including nerve damage, spinal damage, neuro-vascular and other complications involving bacterial infection, anesthesia accident and/or bleeding were reported damage in both procedures APLD and PDCT.

All kinds of minimally invasive herniated disc treatment procedures offer similar functions such as conventional lasers and nuceloplasty aims decompression by make cavities or empty channel. And I.D.E.T use RF coil to hit annulus area to get rid of root branches and bring protein denatured effect. In case of PDCT, with plasma light's feature that has 360 degree ball shape from the target, it can also delivery thermal damage 3-4 $\mathrm{mm}$ to the back from the center of tip of plasma fiber around the region area directly.

We presume that PDCT has better result especially in the long term follow up due to its ability in delivering localized thermal damage to the annulus area. 


\section{CONCLUSION}

PDCT was more effective than APLD 7 months post-operatively in this study, allowing stable decompression and safe minimally invasive operation to an area desired by the operator for the lumbar disc herniation patients. Above methods are considered as a very effective minimally invasive surgery capable of obtaining a considerably satisfactory outcome from the lumbar disc herniation patients, although further long term clinical evaluations are still in need. PDCT may be considered as an effective therapy and may give satisfactory outcome, especially in the longer post-operative period.

\section{REFERENCES}

1. Bonaldi G: Automated percutaneous lumbar discectomy: technique, indications and clinical follow-up in over 1000 patients. Neuroradiology 45:735-743, 2003

2. Botsford, JA: Radiological considerations: patient selection for percutaneous laser disc decompression. J Clin Laser Med Surg 12:255-259,1994

3. Bressler HB, Keyes WJ, Rochon PA, Badley E: The prevalence of low back pain in the elderly. A systemic review of the literature. Spine 24:1813-1819, 1999

4. Cassidy JD, Carroll LJ, Cote P: The Saskatchewan Health and Back Pain Survey: The prevalence of low back pain and related disability in Saskatchewan Adults. Spine 23:1860-1867,1998

5. Chen YC, Lee SH, Chen D: Intradiscal pressure study of percutaneous disc decompression with nucleoplasty in human cadavers. Spine 28:661-665, 2003

6. Choy D, Altman P: Fall of intradiscal pressure with laser ablation. Spine State Art Rev 7:23-29, 1993

7. Choy DS: Percutaneous laser disc decompression (PLDD): twelve years' experience with 752 procedures in 518 patients. J Cin Laser Med Surg 16:325-331,1998

8. Cohen SP, Larkin T, Abdi S, Chang A, Stojanovic M: Risk factors for failure and complications of intradiscal electrothermal therapy: a pilot study. Spine 28:1142-1147, 2003

9. Delamarter RB, Howard MW, Goldstein T, Deutsch AL, Mink JH, Dawson EG: Percutaneous lumbar discectomy: Preoperative and postoperative magnetic resonance imaging. J Bone Joint Surg Am 77:578-584, 1995

10. Djurasovic M, Glassman SD, Dimar JR 2nd, Johnson JR: Vertebral osteonecrosis associated with the use of intradiscal electrothermal therapy: a case report. Spine 27:E325-E328, 2002
11. Iwatsuki K, Yoshimine T, Sasaki M, Yasuda K, Akiyama C, Nakahira R: The effect of laser irradiation for nucleus pulposus: An experimental study. Neurol Res 27:319-323, 2005

12. Javid MJ, Nordby EJ, Ford LT, Hejna WJ, Whisler WW, Burton C, et al: Safety and efficacy of chymopapain (Chymodiactin) in 8 herniated nucleus pulposus with sciatica. Results of a randomized, double-blind study. JAMA 249:2489-2494, 1983

13. Kohlboeck G, Greimel KV, Piotrowski WP, Leibetseder M, Krombholz-Reindl M, Neuhofer R, et al: Prognosis of multifactorial outcome in lumbar discectomy: a prospective longitudinal study investigating patients with disc prolapse. Clin J Pain 20:455?461, 2004

14. Lee J, Lutz GE, Campbell D, Rodeo SA, Wright T: Stability of the lumbar spine after intradiscal electrothermal therapy. Arch Phys Med Rehabil 82:120-122, 2001

15. Lee SH, Derby R, Chen Y, Seo KS, Kim MJ: In vitro measurement of pressure in intervertebral discs and annulus fi brosus with and without annular tears during discography. Spine J 4: 614-618, 2004

16. Maroon JC: Current concepts in minimally invasive discectomy. Neurosurgery 51:S137-S145,2002

17. Nordby EJ, Wright PH, Schofield SR: Safety of chemonucleolysis. Adverse effects reported in the United States. Clin Orthop Relat Res 293:122-134, 1993

18. Ohnmeiss DD, Guyer RD, Hochschuler SH: Laser disc decompre ssion. The importance of proper patient selection. Spine 19: 2054-2058, 1994

19. O’Neill CW, Kurgansky ME, Derby R, Ryan DP: Disc stimulation and patterns of referred pain. Spine 27:2776-2781, 2002

20. Onik G, Helms C, Ginsburg L, Hoaglund FT, Morris J: Percutaneous lumbar diskectomy using a new aspiration probe. AJNR 6:290-293, 1985

21. Onik G, Helms CA, Ginsberg L, Hoaglund FT, Morris J: Percutaneous lumbar diskectomy using a new aspiration probe: Porcine and cadaver model. Radiology 155:251-252, 1985

22. Scholl BM, Theiss SM, Lopez-Ben R, Kraft M: Vertebral osteonecrosis related to intradiscal electrothermal therapy: a case report. Spine 1;28(9):E161-E164, 2003

23. Schenk B, Brouwer PA, van Buchem MA: Experimental basis of percutaneous laser disc decompression (PLDD): a review of literature. Lasers Med Sci 21:245-249, 2006

24. Seung WB, Jeon BC, Lee HK, Song KS: A combined procedure of automated percutaaneous ncleotomy and low dose chemonucleolysis for herniated lumbar disc patient. Korean J Spine 1(4):469-476, 2004

25. Singh V, Derby R: Percutaneous lumbar disc decompression. Pain Physician 9:139-146, 2006

26. Yonezawa T, Onomura T, Kosaka R, Miyaji Y, Tanaka S, Watanabe $\mathrm{H}$, et al: The system and procedures of percutaneous intradiscal laser nucleotomy. Spine 15:1175-1185, 1990 